\title{
Doğumhanede Çalışan Ebeler İçin İsyükü Analizine Dayalı İnsangücü Planlaması
}

\author{
Şirin Özkan' ${ }^{1}$, Meltem Saygılı' ${ }^{2}$ Gökhan Aba ${ }^{1}$
}

'Bandırma Onyedi Eylül Üniversitesi Sağlık Bilimleri Fakültesi, Sağlık Yönetimi Bölümü, Balıkesir, Türkiye ${ }^{2}$ Kırıkkale Üniversitesi Sağlık Bilimleri Fakültesi, Sağlık Yönetimi Bölümü, Kırıkkale, Türkiye

Şirin Özkan

Meltem Saygılı

Gökhan Aba

Illetişim:

Gökhan Aba

Bandırma Onyedi Eylül Üniversitesi Sağık Bilimleri Fakültesi, Sağlık Yönetimi Bölümü, Balıkesir, Türkiye

Tel: +90505 5670484

E-Posta: gokhanaba20@hotmail.com

Gönderilme Tarihi : 16 Kasım 2017

Revizyon Tarihi : 06 Aralık 2017

Kabul Tarihi : : 11 Aralık 2017

\section{ÖZET}

Amaç: Çalışmanın amacı kamu hastanelerinin doğumhane birimleri için ebe ihtiyacını iş yüküne dayalı olarak belirlemektir.

Çalışma planı: Bu araştırmada Kocaeli ilinde doğumhane birimi bulunan 7 hastane incelenmiştir. Hastanelerin doğumhane birimlerinde çalışan toplam ebe sayısı 72 'dir. Anket 72 kişiye ulaştırılmış olup ankete cevap veren kişi sayısı 42'dir (\%58). Hastanelerin ürettikleri hizmetlerin 2016 yılına ait verileri kullanılarak 2017 yılı için gerekli ebe sayısı hesaplanmıştır. Verilerin analizinde, DSÖ tarafından hazırlanmış olan “Workload Indicators of Staffing Need (WISN) Automated Tool 2010" programı kullanılmıştır.

Bulgular: II genelinde doğumhane ebelerinin hastaneler arasındaki dağılımına bakıldığında $A$ doğumhanesinde çalışan ebelerin işyükü oranı 0,60 ; B doğumhanesinde 0,66 ; C doğumhanesinde 2,17; D doğumhanesinde 1,13; E doğumhanesinde 2,$21 ; \mathrm{F}$ doğumhanesinde 2,05 ve $\mathrm{G}$ doğumhanesinde 1,77 olduğu belirlenmiştir.

Sonuç: Bu araştırma ile Kocaeli ilindeki kamu hastanelerindeki doğumhanelerde çalışan ebe sayısının yeterli olduğu, iş yükü oranlarının 1,08 olduğu saptanmıştır. İl genelinde belirlenen standartları karşılamak için gerekenden \%8 daha fazla doğumhanede çalışan ebe olduğu tespit edilmiştir. Ayrıca il genelindeki hastaneler arasında ebe iş yükünün dağılımının dengesiz olduğu tespit edilmiştir.

Anahtar sözcükler: Ebelik, iş yükü, insangücü planlaması

\section{WORKFORCE PLANNING BASED ON AN ANALYSIS OF WORKLOAD FOR MIDWIVES WITHIN DELIVERY ROOMS}

\section{ABSTRACT}

Objective: The aim of this research is to determine the midwives' need for delivery room units in public hospitals based on their workload.

Study Design: Seven hospitals with integral delivery suites in the Kocaeli district were reviewed for this survey. The total number of midwives working in the delivery suites at these hospitals is 72 . The survey was sent to all 72 people, of which $42(58 \%)$ replied. The number of midwives required for 2017 was computed using data on services provided at the hospitals in 2016. The 'Workload Indicators of Staffing Need (WISN) Automated Tool 2010' application created by the WHO was employed to analyse the data.

Results: By investigating the distribution of midwives in delivery rooms across the province, it was found that the workload ratio of the midwives working in the various delivery rooms were delivery room $A=0.60 ; B=0.66 ; C=$ $2.17 ; \mathrm{D}=1.13 ; \mathrm{E}=2.21 ; \mathrm{F}=2.05 ;$ and $\mathrm{G}=1.77$.

Conclusion: It has been shown through this survey that the number of midwives working in the delivery rooms in Kocaeli district is adequate; the workload ratio overall is 1,08 . There are $8 \%$ more delivery room midwives available than the number needed to meet the standards determined for the entire province. The distribution of workload was also found from the same data.

Keywords: Midwifery, workload, workforce planning 
ağlıkta insan kaynaklarını etkileyen karmaşık faktörlerin etkilerini kontrol altında tutabilmek için stratejik planlama gereklidir. Çoğu ülkede görülen sağlık çaış̧anlarının kronik dengesiz dağılımlarının da nedeni, geçmişte uygulanan teknokratik planlamaların etkisiz olması gösterilmektedir (1).

Sağlık insangücü planlamasında, eğitim ve sağlık otoritelerinden, hangi nitelikte ve ne sayıda çalışana ihtiyaç duyulduğu, bu personelin dağılımı ve görevleri konusunda kararlar almaları beklenmektedir. Yetersiz planlama veya plansızlık, sağlık hizmetlerinin, işleyişini ciddi olarak bozmakta, maliyeti arttırmakta, kaynakların dengesiz dağılımına neden olmaktadır. Bunların sonucunda toplumun ihtiyaç duyduğu yerde, zamanda ve hak ettiği nitelikte sağlık hizmeti alması güçleşmektedir (2).

Sağlık insangücü planlamasının temel amacı doğru sayıda, doğru yerde, doğru zamanda, doğru becerilere sahip, doğru motivasyon ve tutumları ile doğru maliyetle, doğru işi yapma idealine ulaşılmasını sağlamaktır. Gelecekte olması öngörülen personel verimliliği ve gerekli mali kaynaklar dikkate alınarak tahminlerde bulunulur (3). İnsangücü planlamasında, sağlık çalışanlarının yeni üstlendiği ve yapmaya devam ettiği işleri göz önünde bulundurmalıdır (4).

Sağlık insangücü kavramı, Dünya Sağlık Örgütü (DSÖ) tarafından 1950'lerden itibaren sağlık sisteminin önemli bir "köşe taşı" olarak tanımlanmış, planlama, yetiştirme ve yönetme (istihdam) olarak 3 ana bileşen belirlenmiştir. İş yüküne dayalı personel ihtiyacı belirlenmesi yöntemi (Workload Indicators of Staffing Need (WISN) sağlık çalışanlarının iş yükünü ve her iş yükü bileşeni için gerekli olan aktivite süresinin belirlenmesi ilkesine dayanır. Bu yöntem, 1984 yılında Peter J. Shipp tarafından stratejik insan kaynakları planlamasında personel projeksiyonlarında kullanmak üzere basit ve hızlı bir yöntem olarak geliştirilmiştir (5). 1998 yılında ise DSÖ tarafından sağlık insangücü planlamasında kullanılmak üzere bir kılavuz yayınlanmıştır (6). Söz konusu kullanım kılavuzu daha çok sağlık bakanlıkları için planlamada yardımcı olmak üzere hazırlanmıştır. O günden bugüne kadar sağlık hizmetlerinde ve yönetiminde birçok değişim gerçekleşmiştir. Son olarak 2010 yılında DSÖ tarafından hazırlanan rehberde yöntem yerelleşmenin yaygın olduğu sağlık sistemine sahip ülkelerde de kullanılmak üzere gözden geçirilip yeniden düzenlenmiştir. Son hali sağlık sisteminde birçok aşamasında çalışan sağlık yöneticilerinin kullanabileceği şekilde geliştirilmiştir (7).

DSÖ ve UNICEF, Ana-Çocuk Sağlığı ve Temel Sağlık Hizmetlerinin başarı ile yürütülmesinde "ebelik mesleğinin güçlendirilmesi" üzerinde vurgu yapmakta ve 21.Yüzyılda Herkes İçin Sağlık Hedeflerinden üçüncüsü olan "Yaşama Sağlıklı Başlanması Hedefi"nin gerçekleştirilmesinde ebelik mesleğinin önemine dikkat çekmektedir (8). Uluslararası Ebeler Konfederasyonu'na göre ebe; her ülkede ebelik eğitimini başarıyla tamamladıktan sonra kendine yasal olarak çalışma onayı verilen, gebelik, doğum ve doğum sonrası dönemlerinde annelere gerekli izlemi yapan, bakım veren ve önerilerde bulunan, kendi sorumluluğundaki doğumları yaptıran, yenidoğana ve bebeğe bakım verebilme yeteneğine sahip olan sağlık profesyonelidir (9).

Sağlık insan kaynaklarının sayısal yeterliliğinin birinci basamak sağlık hizmetlerinde etkisini incelemeye yönelik 117 ülkeyi kapsayan ve DSÖ verileri kullanılarak yapılan bir çalışmada sağlık insan kaynaklarının anne ölüm oranı, yeni doğan ölüm oranı ve beş yaş altı ölüm oranlarına etkisi incelenmiştir. Sağlıkta insan kaynakları yoğunluğunun anne ölüm oranı, yeni doğan ölüm oranı ve beş yaş altı ölüm oranlarını önemli ölçüde etkilediği gözlemlenmiştir. İyi yetişmiş ve yeterli sayıdaki sağlık personelinin risk altındaki annelerde meydana gelebilecek hastalıkları tespit etmede daha iyi olabileceği, anne ve bebek ölümlerinin azaltılması için sağlık insan kaynakları yatırımlarının arttırılması önerilmiştir (10). Benzer şekilde Gürcistan'da yapılan ulusal aşılama programında düşük aşılama oranı nedenleri olarak yetersiz finansman, düşük kaliteli aşılar, yetersiz aşı uygulamaları, zayıf sağlık hizmetleri sistemi ile birlikte en önemli neden olarak insan kaynaklarındaki yetersizlikler gösterilmiştir (11).

Ebelik hizmeti veren sağlık çalışanlarının doğumhaneler için iş yükleri, yıllık hasta hacimleri, vaka karışımları ve çaIışanlar ele alınarak yapılacak kurumlar arası karşılaştırmalar ya da hasta sayılarının ve onlarla ilişkili iş yüklerinin devamlı gözlenmesi ve gözlem sayıları ile çalışanların beceri seviyelerinin karşılaştııılması ile belirlenebilir (12).

Ebelerin doğumhanelerde, hasta güvenliği ilkeleri doğrultusunda, anne ve bebeğin sağlığını riske atmadan doğum eylemine yardımcı olmaları, doğum sonrası gelişebilecek acil durumlara uygun şekilde müdahale edebilmeleri ve bütün doğum eylemi sürecinde, kaliteli ve eksiksiz hizmet vermelerinin uygun çalışma koşulları ve zorlayıcı olmayan iş yükleri ile bağlantılı olduğu bilinmektedir. Bu araştırma ile hastanelerinin doğumhane birimleri için ebe intiyacını iş yüküne dayalı olarak belirlenmesi amaçlanmıştır.

\section{Yöntem}

\section{Araştırmanın amacı}

Bu çalışmada, Kocaeli ilinde Sağlık Bakanlığına bağlı hastanelerin doğumhane birimlerinde çalışan ebe ihtiyacının iş yüküne dayalı olarak belirlenmesi amaçlanmıştır. 


\section{Araştırma soruları}

Kocaeli ilindeki kamu hastanelerinin doğumhane birimlerinde ebe ihtiyacı var mıdır? İ genelindeki hastaneler arasında ebe iş yükü dağılımı dengeli midir?

\section{Araştırmanın yapıldığı yer ve özellikleri}

Kocaeli ilindeki Sağlık Bakanlığına bağlı toplam hastane sayısı dokuz olup bunların yedi tanesinde doğumhane bulunmaktadır. Araştırma bu yedi hastanede bulunan doğumhanelerde gerçekleştirilmiştir. Hastanelerin ürettikleri hizmetlerin 2016 yılına ait verileri kullanılarak 2017 yılı için gerekli ebe sayısı hesaplanmıştır.

\section{Araştırmanın evreni ve örneklemi}

Çalışmanın evrenini, Kocaeli ilindeki Sağlık Bakanlığı’na bağlı tüm hastanelerin doğumhanelerinde çalışan ebeler oluşturmaktadır. Doğumhanelerde çalışan toplam ebe sayısı72'dir. Evrenin tamamı araştırma kapsamına dâhil edilmiştir. Anket 72 kişiye ulaştırılmış olup ankete cevap veren kişi sayısı 42'dir. Evrenin \%58'ine ulaşılmıştır.

\section{Verilerin toplanması}

Bu araştırmada veri toplama aracı olarak anket kullanılmıştır. Ebelere uygulanan anketin birinci bölümde ebelerin mesleki faaliyetleri tanımlamaları ve bu faaliyetleri gerçekleştirmek için gerekli olan ortalama süreleri belirlemeleri istenmiştir. İkinci bölümde ise aktif çalışma süresi içinde eğitim-araştırma faaliyetleri (kongre, eğitim, bilimsel çalışmalar) ile diğer faaliyetler (idari işler, özel aktiviteler, çay molası ve toplantılar) için gereken sürenin ne kadar olması gerektiği sorulmuştur. Her bir faaliyet için harcanan süre, görüşme formlarına dakika olarak geçirilmiştir. Hastanelerin 2016 yılına ait hizmet çıktılarına ilişkin verileri hastane kayıtları ve raporlardan elde edilmiştir.

\section{Verilerin değerlendirilmesi}

Elde edilen verilerin analizinde, DSÖ tarafından hazırlanmış olan "Workload Indicators of Staffing Need (WISN) Automated Tool 2010" programı kullanılmıştır (7). İşyüküne dayalı personel ihtiyacı hesaplanması aşamaları aşağıdaki aşamalarda gerçekleşmiştir;

- Ebelerin öncelikle aktif olarak çalıştığı süre belirlenmiştir. Devlet Memurları Kanunu'nun 99. maddesine göre haftalık çalışma süresi 40 saat olarak düzenlendiğinden araştırma kapsamında ebe ihtiyacı hesaplamalarında haftalık çalışma süresi 40 saat olarak ele alınmıştır.

- Ebelerin hastanedeki iş yükünü oluşturan faaliyetler tanımlanmıştır.

- Ebelerin iş yükünü oluşturan belirli bir faaliyeti yapmak için, iyi yetişmiş bir meslek mensubunun ülke koşullarında ortalama olarak kullanacağı süre yani birim zaman (aktivite standardı) belirlenmiştir. Ebelerin görüşüme sırasında önerdikleri sürelerle standartlar belirlenmiştir. Görüşme formlarının analizi aritmetik ortalama alınarak yapılmıştır.

- Hizmet istatistiklerinde yer alan faaliyetler için belirlenmiş aktivite standartları kullanılarak standart iş yükü hesaplanmıştır. Standart iş yükü aşağıdaki formül ile hesaplanır.

Standart iş yükü: Yıllık toplam çalışma süresi (dakika)/ Aktivite standardı (dakika)

Hesaplanan personel ihtiyacı: Yıllık gerçekleşen faaliyet sayısı/ Standart İşyükü

- Hizmet istatistiklerinde yer almayan faaliyetlerin iş yükü hesaplanmasında kategori ayarlama faktörü ve bireysel ayarlama faktörleri kullanılmıştır.

- Son olarak aktivite standartları, kategori ayarlama çarpanı, bireysel ayarlama faktörü ve hizmet istatistikleri kullanılarak personel ihtiyacı hesaplanmıştır.

Personel ihtiyacı: (Hizmet İstatistiklerinde Yer Alan Faaliyetlerine İlişkin Toplam Personel İhtiyacı* Kategori Ayarlama Faktörü) + Bireysel Ayarlama Faktörü

\section{İşyükü oranın yorumlanması}

Fark= mevcut -hesaplanan ihtiyaç; ihtiyaç ya da fazlalık olup olmadığını gösterir.

İşyükü (WISN) Oranı= mevcut/ hesaplanan ihtiyaç; her bir personelin maruz kaldığı iş yükü baskısını gösterir.

\section{Bulunan WISN değerlerine göre personel yeterliliği sı- nırları aşağıda verilmiştir.}

WISN = 1 ise; ihtiyaç = mevcut personel sayısına eşittir.

WISN < 1 ise; standartları karşılamak için personel sayısı yetersizdir.

Örneğin A Hastanesi için ebe WISN oranı=0,60 tır. Bu ihtiyaç duyulan personelin ancak \%60'nın mevcut olduğunu ya da standartların ancak \%60'na ulaşılabildiğini gösterir.

WISN > 1 ise; standartları karşılamak için gerektiğinden fazla personel var demektir.

Örneğin araştırma kapsamındaki C Hastanesi için ebelerin WISN oranı=2,17'dir. Bu durum belirlenen standartları karşılamak için gerekenden \%117 daha fazla personel olduğunu gösterir. 


\section{Bulgular}

Ebelerin yıl içinde aktif olarak çalıştığı süre saat olarak belirlenmiştir. Tablo 1'de ebelerin aktif çalışma süresinin nasıl hesaplandığı ve bunlara ait süreler verilmiştir. Aktif çalışma süresi haftada 40 saat olacak şekilde beş gün ve günde sekiz saat üzerinden ele alınmıştır. Çalışıımayan gün sayısı çıkartıldıktan sonra;

Aktif Çalışma Süresi $=213$ gün= 42,6 hafta $=1704$ saat olarak belirlenmiştir.

Ebelerin yıllık ortalama 25 gün yıllık izin ve 10 gün de hastalık izni kullandığı belirlenmiştir. Yıllık izin ve ortalama gün sayısı hesaplamasında ebelerden gelen cevaplar doğrultusunda aritmetik ortalama kullanılmıştır.

Ebelerin yedi hastanedeki işyüküne göre personel ihtiyacı belirlemesi her hastane için ayrı ayrı yapılmıştır. Tablo 2 ve Tablo 3'de sadece A hastanesine ilişkin yıllık

$\begin{array}{lccc}\text { Tabılo 1. Ebelerin yıllık aktif çalışma süresi } & \\ \text { Haftalık Çalışılan Gün Sayısı } & 5 & \text { Özel İzin } & 0 \\ \text { Günlük Çalışılan Saat Sayısı } & 8 & \text { Toplam Çalışılmayan Gün } & 47 \\ \text { Yıllık İzin } & 25 & \text { Toplam Çalışılmayan Hafta } & 9,4 \\ \text { Resmi Tatil } & 12 & \text { Çalışılan Gün } & 213 \\ \text { Hastalık İzni } & 10 & \text { Çalışılan Hafta } & 42,6 \\ \text { Yılık Çalışılan Toplam Saat } & & & \mathbf{1 7 0 4}\end{array}$

gerçekleştirilen faaliyet sayısı ve personel ihtiyacına ilişkin analiz sonuçları ayrıntılı olarak verilmiştir. Diğer hastanelere ilişkin sonuçlar Tablo 4'de yer almaktadır.

Tablo 2'de hastanelerin doğumhanelerinde çalışan ebelerin yaptığı işlere ilişkin bulgular gösterilmiştir. Buna göre, tedavi ve tedavinin hemşire gözlem formuna geçirilmesi faaliyeti ortalama sekiz dakikada gerçekleştirilebilmektedir. Yıllık gerçekleştirilen faaliyet sayısı 3652 olduğundan, personel ihtiyacı 0,29 kişidir. Bir sezaryene hazırlık faaliyeti ortalama 15 dakikada gerçekleştirilebilmektedir. Yıllık gerçekleştirilen faaliyet sayısı 865 olduğundan, bu faaliyetle ilgili personel intiyacı 0,13 kişidir. Bir doğum yaptırılması, bebeklerin tartılması, temizlenmesi ve yatağa alınması faaliyeti ortalama 80 dakikada gerçekleştirilebilmektedir. Yıllık gerçekleştirilen faaliyet sayısı 3631 olduğundan, bu faaliyetle ilgili personel ihtiyacı 2,84 kişidir. Bir loğusa kanama kontrolü faaliyeti ortalama 18 dakikada gerçekleştirilebilmektedir. Yıllık gerçekleştirilen faaliyet sayısı 3652 olduğundan, bu faaliyetle ilgili personel ihtiyacı 0,64 kişidir. Bir hekim vizitine eşlik etme faaliyeti ortalama 15 dakikada gerçekleştirilebilmektedir. Yıllık gerçekleştirilen faaliyet sayısı 3652 olduğundan, bu faaliyetle ilgili personel intiyacı 0,54 kişidir. Bir NST faaliyeti ortalama 20 dakikada gerçekleştirilebilmektedir. Yıllık gerçekleştirilen faaliyet sayısı 5469 olduğundan, bu faaliyetle ilgili personel intiyacı 1,07 kişidir. Vital bulguların takibi faaliyeti ortalama 20 dakikada gerçekleştirilebilmektedir. Yıllık gerçekleştirilen faaliyet sayısı 2750 olduğundan, bu faaliyetle ilgili

Tablo 2. Hizmet istatistiklerinde yer alan faaliyetlere ilişkin ebe intiyacı (A Hastanesi Doğumhanesi)

\begin{tabular}{|c|c|c|c|c|}
\hline Faaliyet Adı & $\begin{array}{l}\text { Yıllık Gerçekleşen } \\
\text { Faaliyet Sayısı }\end{array}$ & $\begin{array}{l}\text { Faaliyet } \\
\text { standardı }\end{array}$ & Birimi & $\begin{array}{c}\text { Personel } \\
\text { ihtiyacı }\end{array}$ \\
\hline Tedavi ve tedavinin hemşire gözlem formuna geçirilmesi & 3652 & 8 & $\mathrm{dk} /$ hasta & 0,29 \\
\hline Sezaryene hazırlık & 865 & 15 & dk/hasta & 0,13 \\
\hline $\begin{array}{l}\text { Doğum yaptıııması, bebeklerin tartıması, temizlenmesi } \\
\text { ve yatağa alınması }\end{array}$ & 3631 & 80 & dk/hasta & 2,84 \\
\hline Loğusa kanama kontrolü & 3652 & 18 & $\mathrm{dk} / \mathrm{hasta}$ & 0,64 \\
\hline Hekim vizitine eşlik etmek & 3652 & 15 & dk/hasta & 0,54 \\
\hline NST & 5469 & 20 & dk/örnek & 1,07 \\
\hline Vital bulguların takibi & 2750 & 20 & dk/hasta & 0,54 \\
\hline Onam formu düzenlenmesi & 3652 & 10 & $\mathrm{dk} / \mathrm{hasta}$ & 0,36 \\
\hline Hasta yakınlarını bilgilendirme & 2750 & 29 & $\mathrm{dk} /$ hasta & 0,78 \\
\hline ÇKS & 2766 & 85 & $\mathrm{dk} /$ hasta & 2,3 \\
\hline Ölen hasta & 21 & 30 & dk/hasta & 0,01 \\
\hline Taburcu işlemleri & 2766 & 15 & $\mathrm{dk} /$ hasta & 0,41 \\
\hline Hasta yatış// karşılama & 3652 & 20 & $\mathrm{dk} /$ hasta & 0,71 \\
\hline Toplam ihtiyaç & & & & 10,62 \\
\hline
\end{tabular}


Tablo 3. Hizmet istatistiklerinde yer almayan faaliyetlere ilişkin ebe ihtiyacı (A Hastanesi Doğumhanesi)

\begin{tabular}{|c|c|c|c|c|}
\hline Faaliyet Adı & & İş yükü & Birim & Kategori Ayarlama Çarpanı \\
\hline Çay molası & & 90 & $\mathrm{dk} /$ gün & 0,19 \\
\hline Hizmet içi eğitim & & 20 & saat/yll & 0,01 \\
\hline Kongreler & & 5 & gün/yıl & 0,02 \\
\hline Nöbet tesliminin alınması & & 55 & $\mathrm{dk} /$ gün & 0,11 \\
\hline Toplantılar & & 1 & saat/ay & 0,01 \\
\hline Diğer aktiviteler/özel işler & & 1 & saat/ay & 0,01 \\
\hline Toplam kategori ayarlama çarpanı & & & & 0,35 \\
\hline Kategori ayarlama faktörü & & & & 1,54 \\
\hline Faaliyet Adı & Faaliyeti Yapacak Kişi Sayısı & İş yükü & Birim & Bireysel Ayarlama Çarpanı \\
\hline Birim depo kontrolü & 2 & 0,5 & saat/hafta & 520 \\
\hline İlaç kontrolü & 1 & 0,5 & saat/hafta & 260 \\
\hline Malzeme ilaç kontrolü ve yazımı & 1 & 20 & $\mathrm{dk} /$ gün & 86,67 \\
\hline Nöbet teslim defterinin yazıIması & 1 & 8 & $\mathrm{dk} /$ gün & 34,67 \\
\hline $\begin{array}{l}\text { Sarf malzemelerinin tamamlanması } \\
\text { hazırlanması }\end{array}$ & 1 & 20 & $\mathrm{dk} /$ gün & 86,67 \\
\hline Sorumlu ebe & 1 & 8 & saat/gün & 2,080 \\
\hline Tıbbi cihaz kontrolü & 1 & 0,3 & saat/hafta & 156 \\
\hline Toplam bireysel ayarlama çarpanı & & & & 3224,01 \\
\hline Bireysel ayarlama faktörü & & & & 1,89 \\
\hline Mevcut personel sayısı & 11 & \multicolumn{2}{|c|}{ Toplam Personel intiyacı } & 18,23 \\
\hline
\end{tabular}

Tablo 4. Kocaeli ili hastanelerindeki doğumhanelerde çalışan ebelerin işyükü dağılımı

\begin{tabular}{lccc} 
Hastane/Doğumhane adı & $\begin{array}{c}\text { Mevcut } \\
\text { personel }\end{array}$ & $\begin{array}{c}\text { Personel } \\
\text { ihtiyacı }\end{array}$ & $\begin{array}{c}\text { Işyükü oranı } \\
\text { (WISN) }\end{array}$ \\
\hline A doğumhanesi & 11 & 18,23 & 0,6 \\
B doğumhanesi & 14 & 21,31 & 0,66 \\
C doğumhanesi & 14 & 6,46 & 2,17 \\
D doğumhanesi & 9 & 7,98 & 1,13 \\
E doğumhanesi & 5 & 2,26 & 2,21 \\
F doğumhanesi & 4 & 1,95 & 2,05 \\
G doğumhanesi & 15 & 8,48 & 1,77 \\
Toplam & 72 & 66,67 & 1,08
\end{tabular}

personel ihtiyacı 0,54 kişidir. Bir onam formu düzenlenmesi faaliyeti ortalama 10 dakikada gerçekleştirilebilmektedir. Yıllık gerçekleştirilen faaliyet sayısı 3652 olduğundan, bu faaliyetle ilgili personel ihtiyacı 0,36 kişidir. Bir hasta yakınlarını bilgilendirme faaliyeti ortalama 29 dakikada gerçekleştirilebilmektedir. Yıllık gerçekleştirilen faaliyet sayısı 2750 olduğundan, bu faaliyetle ilgili personel ihtiyacı 0,78 kişidir. Bir ÇKS faaliyeti ortalama 85 dakikada gerçekleştirilebilmektedir. Yıllık gerçekleştirilen faaliyet sayısı 2766 olduğundan, bu faaliyetle ilgili personel ihtiyacı 2,3 kişidir. Bir ölen hastanın toplanması faaliyeti ortalama 30 dakikada gerçekleştirilebilmektedir. Yıllık gerçekleştirilen faaliyet sayısı 21 olduğundan, bu faaliyetle ilgili personel intiyacı 0,01 kişidir. Bir taburcu işlemi faaliyeti ortalama 15 dakikada gerçekleştirilebilmektedir. Yıllık gerçekleştirilen faaliyet sayısı 2766 olduğundan, bu faaliyetle ilgili personel ihtiyacı 0,41 kişidir. Bir hasta yatışı/karşılama faaliyeti ortalama 20 dakikada gerçekleştirilebilmektedir. Yıllık gerçekleştirilen faaliyet sayısı 3652 olduğundan, bu faaliyetle ilgili personel ihtiyacı 0,71 kişidir.

Ebelerin hizmet istatistiklerinde yer almayan faaliyetlerine ilişkin personel intiyacı belirlemesi Tablo 3'de yer almaktadır. Doğumhane ebelerinin çay molası için günde 90 dakika, hizmet içi eğitim için yılda 20 saat, kongreler için yılda beş gün, nöbet tesliminin alınması için günde 55 dakika, toplantılar için ayda bir saat, diğer aktiviteler ve özel işler için ayda bir saat ayırdıkları saptanmıştır. Bu durumda kategori ayarlama çarpanları ise sırasıyla; çay molası 
için 0,19; hizmet içi eğitim için 0,01 ; kongreler için 0,02 ; nöbet tesliminin alınması için 0,11 ; toplantılar için 0,01 ; diğer aktiviteler ve özel işler için 0,01'dir. Toplam kategori ayarlama çarpanının 0,35; kategori ayarlama faktörünün 1,54 olduğu hesaplanmıştır. Ayrıca doğumhanede çalışan ebelerinden sadece iki tanesinin birim depo kontrolü için haftada yarım saat, bir tanesinin ilaç kontrolü için ayda yarım saat, malzeme ilaç kontrolü ve yazımı için günde 20 dakika, nöbet teslim defterinin yazılması için günde sekiz dakika, sarf malzemelerinin hazırlanması için günde 20 dakika, sorumlu ebelik görevi için günde sekiz saat, tıbbi cihaz kontrolü için haftada 0,3 saat harcadığı belirlenmiştir. Aktivitelerle ilgili bireysel ayarlama çarpanları ise sırasıyla birim depo kontrolü için 520; ilaç kontrolü için 260; malzeme ilaç kontrolü ve yazımı için 86,67 ; nöbet teslim defterinin yazılması için 34,67; sarf malzemelerinin hazırlanması için 86,67; sorumlu ebelik görevi için 2,080; tıbbi cihaz kontrolü için 156 olduğu saptanmıştır. Toplam bireysel ayarlama çarpanının 3224,01; bireysel ayarlama faktörünün ise 1,89 olduğu saptanmıştır. Sonuç olarak A Hastanesinin toplam doğumhanede çalışması gereken ebe ihtiyacı 18,23 kişi olarak saptanmıştır.

Doğumhanede çalışan ebelerin il geneli işyükü dağılımı incelendiğinde (Tablo 4); En yüksek iş yükü oranı $A$ doğumhanesinde olup 0,60 olarak hesaplanmıştır. Bu hastanede belirlenen standartları karşılamak için gereken kişi sayısının sadece \%60'nın mevcut olduğu saptanmıştır. Bu hastanede, il genelinde belirlenen aktivite standartlarının ancak \%60'na ulaşılabildiği belirlenmiştir. İl genelinde doğumhane ebelerinin hastaneler arasındaki dağılımına bakıldığında $A$ doğumhanesinde çalışan ebelerin işyükü oranı 0,$60 ; B$ doğumhanesinde 0,$66 ; C$ doğumhanesinde 2,17; $D$ doğumhanesinde 1,13; $E$ doğumhanesinde 2,$21 ; F$ doğumhanesinde 2,05 ve $G$ doğumhanesinde 1,77 olduğu belirlenmiştir.

\section{Tartışma}

Kocaeli ili geneli için mevcut doğumhanelerde çalışan ebe sayısı toplam 72'dir. İş yüküne dayalı ihtiyacının 66,67 yani yaklaşık toplam 67 kişi olduğu ve iş yükü oranının ortalama 1,08 olduğu saptanmıştır. II genelinde belirlenen standartları karşılamak için gerekenden \%8 daha fazla personel olduğu saptanmıştır. İl genelinde doğumhane ebelerinin hastaneler arasındaki dağılımına bakıldığında $A$ doğumhanesinde iş yükü oranı 0,60 iken, üç km mesafedeki $C$ doğumhanesinde iş yükü oranının 2,17 olduğu belirlenmiştir. Yine benzer şekilde B doğumhanesinde çalışan ebelerin işyükü oranın 0,66 iken dört km mesafedeki $F$ hastanesinde çalışan doğumhane ebelerinin iş yükü oranı 2,05 olduğu görünmektedir. III genelinde doğumhaneler arası işyükü dağılımında dengesizlik olduğu belirlenmiştir. Dengesiz dağılım yüksek, orta ve düşük gelirli tüm ülkelerde sağlık hizmetlerinde hakkaniyetsizliğe neden olan bir konudur (13). Buna istinaden $\mathrm{C}$ hastanesindeki ebelerden altı tanesi $\mathrm{A}$ hastanesinde görevlendirilebilir.

Bu araştırmada ebelerin iş yükünü oluşturan faaliyetlerin; tedavi ve tedavinin hemşire gözlem formuna geçirilmesi, annenin sezaryene hazırlanması, doğum yaptırılması, bebeklerin tartılması, temizlenmesi ve yatağa alınması, loğusa kanama kontrolü, hekim vizitine eşlik etmek, NST, vital bulguların takibi, onam formunun düzenlenmesi, hasta yakınlarını bilgilendirme, ÇKS, ölen hasta, taburcu işlemleri, hasta yatışı/ karşılama, birim depo kontrolü, ilaç kontrolü, malzeme ilaç kontrolü ve yazımı, nöbet teslim defterinin yazılması, sarf malzemelerinin tamamlanması hazırlanması ve tıbbi cihaz kontrolü olduğu belirlenmiştir. Doğumhanelerde iş yükü kabul edilebilir düzeyde olduğu durumlarda ebelerin mesleki gelişimlerinin desteklenmesi, vaka tartışması, bilimsel çalışmalar, eğitim ve kongreler için vakit ayrılabileceği düşünülmektedir.

Ingiltere'de yapılan bağımsız araştırma bulguları güvenli annelik hizmetlerine ilişkin önemli değişimler olduğunu göstermektedir. Özetle bu bulgular; 2002 yılından bu yana doğum sayısının artması, gebelik komplikasyonlarının daha yüksek oranda görüldüğü 35 yaş üzeri anne sayısının artması, yardımcı üreme tekniklerinin gelişmesiyle birlikte çoğul gebelik oranlarının artması, obez gebe oranlarının artması, ciddi çocukluk dönemi hastalıklarından (lösemi vb.) kurtulmuş ve çocuk sahibi olmuş gebelik ve doğumda ekstra bakıma intiyaç duyan kadınların sayısının, sezaryen oranlarının artması, toplumsal ve etnik çeşitliliğin artmasıyla birlikte iletişim zorlukları, doğum öncesi bakımdaki sosyal ve klinik zorlukların daha fazla ortaya çıkması şeklindedir (14).

Literatür incelendiğinde ebelerin çalışma saatleriyle ilgili ülkelerarası karşılaştırma yapılabilecek bir kaynak hemen hemen yoktur. Ancak, Paterson ve arkadaşlarının (2010) Avustralya'daki bir çalışmasında ortalama ebe çalışma saatleri haftada 28,7 saat olarak bulunmuştur (15). Hollanda'da birinci basamakta çalışan ebelerin işyüklerinin araştırıldığı başka bir çalışmada ebelerin haftalık ortalama çalışma saatleri 29 saat olarak hesaplanmıştır (16). Ebelerin doğum için harcadıkları ortalama zamanla ilgili veriler yine kısıtlı olmakla birlikte eski kaynaklara başvurulabilir. Örneğin, Ball ve Washbrook (1996) tarafından 
yapılan çalışmada yapılan iş miktarı baz alındığında ebelerin antenatal bakım için anne başına dokuz saat harcadıkları, evde doğumlarda doğum süreci için (ücretli ikinci bir ebenin dahil olduğu durumlarda) 17 saat harcadıkları ve postpartum bakım için ise 10 ile 15 saat harcadıkları, toplamda normal ve düşük riskli gebelik durumlarında ortalama 38 saat çalıştıkları ve komplike/yüksek riskli gebelik durumlarında ise bu sürecin 43 saate yükseldiği ifade edilmektedir (17).

Wiegers ve arkadaşları (2014) tarafından yapılan çalışmada, Hollanda'da birinci basamak sağlık hizmetlerinde ebelerin haftada ortalama 32,6 saat iş yerinde çalışmakta ve çalışma sürelerinin yaklaşık \%67'si (haftada yaklaşık 22 saat) hasta ile ilgili faaliyetlerde harcadıklarını belirlemişlerdir. 7/24 telefonlara cevap vermek zorunda olduklarından iş yeri dışında 26 saat telefon görüşmesi ile birlikte ortalama bir ebenin toplam çalışma saatin haftada yaklaşık 59 saat olduğu belirlenmiştir. 2001 yılı verileri ile kıyaslandığında, bir ebenin iş yerinde ortalama çalışma saatleri dört saat artarken ( 29 'dan 32,6 saate arttığı), aktif çalışma süresinin ise toplam saat altı saat azaldığı (65'den 59 saate düştüğü) tespit edilmiştir. 2001-2010 yılları karşılaştırıldığında, ebelerin direkt hasta bakımı ile ilgili faaliyetlerde daha az vakit geçirdiği (\%75'ten \%67 ye düşüş) gözlenmiştir. 2009'da bir ebe ortalama iş yükü, rezervasyonda 99 müşteri, emek başında 56, doğumda 33 ve doğum sonrası bakımda 90 müşteridir. Ebelerin, 2001 yılından 2010'aiş yerinde ortalama çalıştıkları saatlerin arttığı, ancak bu çalışma saatlerini hasta ile ilişkili olmayan faaliyetler oluşturduğu işyükünden kaynaklandığı belirlenmiştir (18).

Bauman ve diğerlerinin çalışmasında ise meslek örgütlerinin insan kaynakları planlamasında aktif hale getirilmesi gerektiği sonucuna varılmıştır (19). Lopes ve arkadaşlarının (2015) yürüttükleri araştırmada meslek örgütlerinin ebe-hemşire planlaması ve sağlık politikası için insan kaynaklarını desteklemek için kullandıkları araçlar ve yaklaşımları incelemek için yapılan araştırmada meslek örgütlerinin planlama süreçlerine katılımının yetersiz olduğu belirlenmiştir. Araştırmaya 67 (\%71) ülkeyi temsil eden 73 (\%68) ebe derneği katılmıştır. Çoğu ülkede (\%95), üreme, anne ve yenidoğan sağlığının sağlanmasını belirlemek sağlık bakanlıkları tarafından yapılan merkezi planlama surecinde diğerler dernekler arasında ebe derneklerini de dâhil etmektedirler. Ancak derneklerin sadece üçte ikisinden azının planlama ve politik kararlara katııım sağlayabildiği belirlenmiştir. Katılımcı oldukları planlama süreçleri, üreme, maternal ve yeni doğan planı (\%63), ulusal sağlık stratejik planı (\%58) ve sağlık insan kaynaklarıdır (\%52)
Ebelik dernekleri, gerekli ebe sayısını hesaplamak için kullanılan sağlık yaklaşımları için insan kaynaklarının farkında olmadığı ve planlama sürecine katılımları sırasında ölçütler, kılavuzlar ve destek araçlarının kullanımının düşük olduğunu belirlenmiştir. Ebelik dernekleri, cinsel sağlık, üreme, anne sağlığı ve yenidoğan sağlığında kilit rol oynamaktadırlar. Bu nedenle, politika geliştirme, planlama sürecine ve sağlık hizmetlerinin ulaşılabilirliğinin arttıııması konularında katkıda bulunma kapasitesi yüksektir (20). Türkiye'de de ebe iş gücü planlaması, anne ve çocuk sağlığı politikalarının geliştirilmesi konularında ebelik derneklerinin aktif katılımının desteklenmesinin yararlı olacağı düşünülmektedir.

Sağlık hizmetleri bütün olarak ele alınan bir ekip hizmetidir. Sunulan hizmet, en altta birinci basamak sağlık hizmetlerinin yer aldığı bir piramide benzetilmektedir. Piramidin tabanını ise ebe ve hemşire sayısı oluşturmalıdır (21). Ebeler farklı düzeylerde eğitim almış olmalarına rağmen aynı statüde istihdam edilmektedirler. Değişik düzeylerde mesleki eğitimi almış ebeler aynı işi yapmaktadırlar. Öte taraftan, farklı eğitim ve çalışma koşullarına sahip ebelerin ücret farklıııkları düşüktür. Bu durumun ebelerin motivasyonunu düşürdüğü öngörülmektedir.

Sağlık Bakanlığı tarafından hazırlanan "Sağlıkta İnsan Kaynakları 2023 Vizyonu" çalışmasında Türkiye için sağlıkta insan kaynakları orta vadeli arz ve ihtiyaç projeksiyonu yapılmıştır (22). Buna göre ebe ihtiyacının 2015 yılı için 59.395 olması, 2023 yılı için de 85.077 olması planlanmıştır. Türkiye'de 2016 itibariyle toplam 52.456 ebe aktif olarak çalışmaktadır (23).

Aktif çalışan ebe sayısı verilerine ilişkin OECD istatistikleri incelendiğinde, Türkiye'deki 1000 kişiye düşen ebe sayısı $(0,68)$ OECD ülkeleri ile karşılaştıııldığında sayının kabul edilebilir düzeyde olduğu görülmüştür. OECD ülkelerinde 23 ülke içinde Türkiye'nin 5. sırada olduğu gözlenmiştir (Şekil 1). 1000 canlı doğum başına düşen ebe sayısı istatistiklerinde ise 23 ülke içinde 40,04 ile dokuzuncu sırada olduğu gözlenmiştir (24). Bu sıralama Türkiye için kısa vadede kabul edilebilir olarak yorumlanabilir. Çünkü Türkiye'nin gayri safi yurt içi hâsıla içinde cari sağlık harcamalarına ayırdığı bütçe 2014 yılında sadece $\% 5$ olarak gerçekleşmiştir (25). Türkiye bu oran ile diğer OECD ülkeleri içinde en son sıradadır.

Türkiye'de uluslararası karşılaştırmalar ile değerlendirildiğinde sayısal olarak yeterli olsa bile ülke genelinde ulusal düzeyde, il içi ve kurum içinde iş yükünün dengeli 


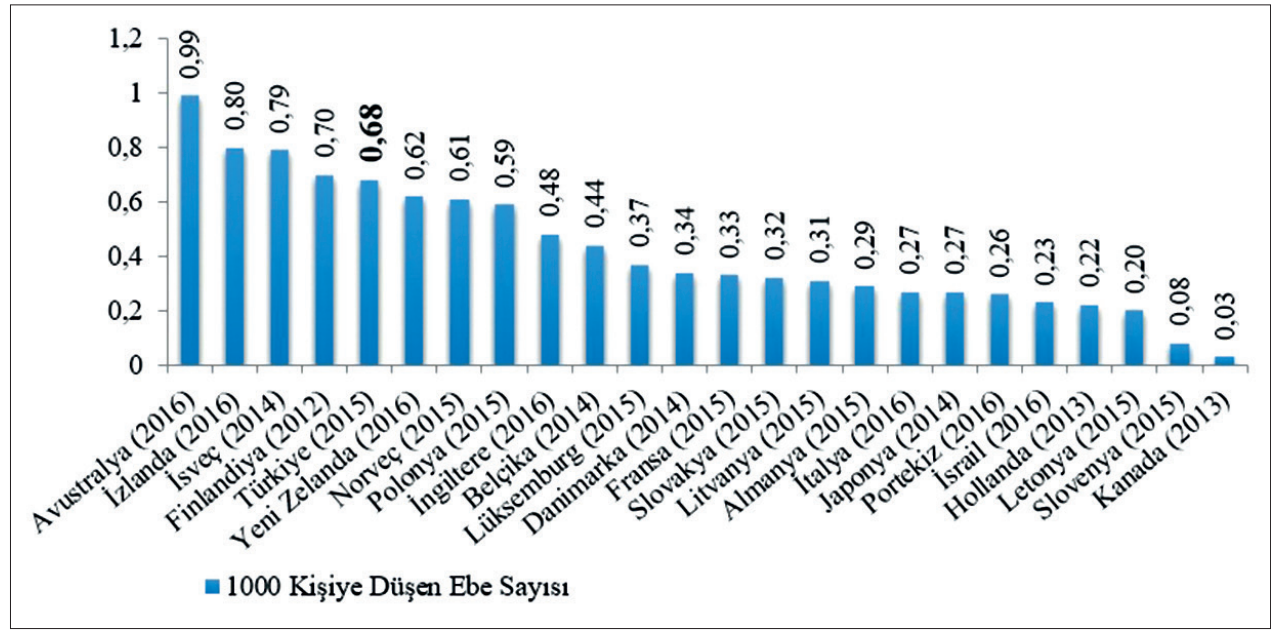

Şekil 1. 1000 Kişiye Düşen Ebe Sayısının OECD Ülkeleri Karşılaştırması *

*Ülkelere ait veriler, erişim tarihi itibariyle, OECD istatistikleri sisteminde yer alan son yillara ilişkin verilerdir. (http://www. oecd.org/health/workforce.htm, Erişim Tarihi: 10.10.2017). dağılımını ve sürekliliği sağlanmalıdır. Bu nedenle insan kaynakları planlaması ve yönetimi dinamik bir süreçtir. Sürekli geliştirilmelidir. Nüfusun değişen sağlık hizmeti intiyacı, ebe iş gücünün niteliği, eğitimi, dengeli dağılımı, verimliliği, maliyetleri, çalışma koşullarının geliştirilmesi, mesleki sorunların çözümü konusunda çalışmalar yapılmalıdır.

\section{Sonuç ve öneriler}

Araştırma sonucunda Kocaeli ilindeki kamu hastanelerindeki doğumhanelerde çalışan ebe sayısının yeterli olduğu, iş yükü oranlarının 1,08 olduğu saptanmıştır. İl genelinde belirlenen standartları karşılamak için gerekenden \%8 daha fazla doğumhanede çalışan ebe olduğunu tespit edilmiştir. Ayrıca il genelindeki hastaneler arasında ebe iş yükünün dağılımının dengeli olmadığı belirlenmiştir.

Ebelik kadın iş gücünün hâkim olduğu meslek gurubudur. Mesleğin kadınlardan oluşması planlamada özellikle göz önünde bulundurulması gereken bir konudur. Düzensiz çalışma saatleri, yüksek iş yükü ve stresli bireylere hizmet verilmesi kadın işgücünü zorlayan unsurlardır. Bu anlamda hastanelerde planlama yapılırken ve çalışma ortamının kadın işgücünün özellikleri açısından değerlendirilmesine ve geliştirilmesine ihtiyaç vardır.
Türkiye'deki mevcut durumda kamu hastaneleri için sağlık iş gücü dağılımı Sağlık Bakanlığı Yönetim Hizmetleri Genel Müdürlüğü tarafından hazırlanan Bakanlık ve Bağlı Kuruluşlar Personel Dağııım/Standart Kadro Cetveli (PDC)'ye göre yapılmaktadır. PDC Sağlık Bakanlığına bağlı personelin iller ve hizmet birimlerine dağılımı önceden belirlenen ilkeler doğrultusunda her yıl yenilenen, kadro ve pozisyon sayısını gösteren tablodur (26). Sağlık Bakanlığı tarafından illerdeki personel ihtiyacını tespit etmeye yönelik hazırlanan Personel Dağılım Cetvelinin iş yüküne dayalı sağlık personeli ihtiyacı esasına göre hazırlanmasının uygun olacağı düşünülmektedir. Ayrıca yerel düzeyde her il kendi insan kaynakları intiyacını iş yüküne dayalı olarak belirlediği talepleri Sağlık Bakanlığına bildirebilir.

Sonuç olarak bu çalışma ile ebe işgücünün etkili planlaması konusunda destek sağlayacak uygulama örneği yapılmıştır. İl genelinde sağlık çalışanlarının dengesiz dağılımın olması işgücü verimsizliğine neden olan, sağlık hizmetlerinde hakkaniyet ilkesine zarar veren ve sağlıkta eşitsizliklere neden olan bir durumdur. Doğum hizmetlerinin kalitesinin ve hasta güvenliğinin temel belirleyicisi olan ebe işgücü ihtiyacının, il içinde ve hastane içindeki dengesiz dağılımının giderilmesi amacıyla hastaneler arası ve hastane içi ebe dağılımının iş yükü oranına göre yapılması ve periyodik olarak güncellenmesi önerilmektedir. 


\section{Kaynaklar}

1. Dussault G, Dubois CA. Human Resources For Health Policies: A Critical Component in Health Policies. Hum Resour Health 2003; $1: 1$.

2. Yükseköğretim Kurulu, Sağlık Bakanlığı, Başbakanlık Devlet Planlama Teşkilatı Müsteşarlığı. Türkiye'de Sağlık Eğitimi ve Sağlık İnsangücü Durum Raporu. Ankara: YÖK Yayın No:2010/1, 2010: 1-282.

3. Hornby P, Ozcan S, Ghimire R. Strategic Plan for Human Resources for Health, 2003 to 2017, Ministry of Health Kathmandu, Nepal, 2003. http://www.unfpa.org/sowmy/resources/docs/library/R095_ MOHNepal_2003_StrategicPlanHRH.pdf Erişim Tarihi: 10.10.2017

4. Dubois CA, McKee M, Nolte E. Human Resources for Health in Europe. European Observatory on Health Systems and Policies Series, New York: Open University Press, 2006: 235-40.

5. Ozcan N, Hornby H. Determining Hospital Workforce Requirements: A Case Study. Human Resources for Health Development Journal (HRDJ) 1999; 3: 210-20.

6. Shipp PJ. Workload Indicators of Staffing Need (WISN): A Manual for Implementation, WHO/HRB/98.2, Geneva: World Health Organization, 1998: 3-24.

7. World Health Organization. (2010). Workload Indicators Of Staffing Need User's Manual. Geneva: Publications of the World Health Organization, 2010: 12-29.

8. Arslan H, Karahan N, Çam Ç. Ebeliğin Doğası ve Doğum Şekli Üzerine Etkisi. Maltepe Üniversitesi Hemşirelik Bilim ve Sanatı Dergisi, 2008;1:54-9.

9. International Confederation of Midwives (ICM). http:// internationalmidwives.org/who-we-are/policy-and-practice/icminternational-definition-of-the-midwife/, Erişim Tarihi 08.06.2017

10. Anand S, Bärnighausen T. Human Resources and Health Outcomes: Cross-Country Econometric Study. Lancet, 2004; 364: 1603-9.

11. Esmail LC, Cohen-Kohler JC, Djibuti M. (2007). Human Resource Management in the Georgian National Immunization Program: A Baseline Assessment. Human Resources for Health, 2007; 5:20.

12. Tucker J, Parry G, Penney G, Page M, Hundley V. Is Midwife Workload Associated With Quality Of Process Of Care (Continuous Electronic Fetal Monitoring [CEFM]) And Neonatal Outcome Indicators? A Prospective Study in Consultant-Led Labour Wards in Scotland. Paediatr Perinat Epidemiol 2003; 17: 369-77.

13. Russell DJ, Humphreys JS, McGrail MR, Cameron W, Williams PJ. The Value of Survival Analyses for Evidence-Based Rural Medical Workforce Planning. Human Resources for Health 2013;11 http:// www.human-resources-health.com/content/11/1/65 Erişim Tarihi 10.10.2017
14. Smith A, Dixon A. Independent Enquiry into The Safety of Maternity Services in England; Whilst This Was Carried Out in England The Findings Were Thought To Be Relevant Across The UK. London: Kings Fund Publication, 2007 https://www.kingsfund.org.uk/sites/default/ files/field/field_document/safety-maternity-services-england-alexsmith-anna-dixon-apr07.pdf Erişim Tarihi: 01.10.2017

15. Paterson JL, Dorrian J, Pincombe J, Grech C, Dawson D. Mood Change And Perception of Workload in Australian Midwives. Industrial Health 2010; 48: 381-9.

16. Wiegers TA. Workload of Primary-Care Midwives. Midwifery 2007;23:425-32

17. Ball JA, Washbrook M. Birthrate Plus: A Framework for Workforce Planning and Decision Making for Midwifery Services. Cheshire: Books for Midwives Press/Elsevier Press, 1996: 159-73.

18. Wiegers TA, Warmelink JC, Spelten ER, Klomp T, Hutton EK. Work and workload of Dutch primary care midwives in 2010. Midwifery 2014;30: 991-7.

19. Baumann A. The Impact of Turnover and the Benefit of Stability in the Nursing Workforce. Geneva: International Centre for Human Resources in Nursing, International Council of Nurses, 2010: 19-22.

20. Lopes SC, Titulaer P, Bokosi M, Homer CS, ten Hoope-Bender P. The Involvement of Midwives Associations in Policy and Planning about The Midwifery Workforce: A Global Survey. Midwifery 2015;31:1096-103.

21. Kılıç B. Türkiye İçin Sağlık İnsangücü Planlaması ve İstihdam Politikaları. TSK Koruyucu Hekimlik Bülteni 2007; 6: 501-14.

22. T.C. Sağlık Bakanlığı, Refik Saydam Hıfzıssıhha Merkezi Başkanlığı Hıfzıssıhha Mektebi Müdürlüğü. Sağlıkta İnsan Kaynakları 2023 Vizyonu, Ankara: Sağlık Bakanlığı Yayın No: 851, 2011: 1-71.

23. T.C. Sağlık Bakanlığı. Sağlık İstatistikleri Yıllığı 2016 Haber Bülteni, 2017. http://www.metaveri.saglik.gov.tr/book/SIY_2016_Haber_ Bulteni.pdf Erişim Tarihi: 19.09.2017

24. OECD Health, 2017. http://www.oecd.org/health/workforce.htm Erişim Tarihi: 10.10.2017

25. T.C. Sağlık Bakanlığı. Sağlık İstatistikleri Yılığı 2015, Sağlık Bakanlığı Yayın No:1054, Ankara: Sistem Ofset Basım Yayın, 2016: 183-85, 212.

26. T.C. Sağlık Bakanlığı. Sağlık 2006, Sağlık Bakanlığı Faaliyet Raporu, Sağlık Bakanlığı Strateji Geliştirme Başkanlığı, Ankara, 2007: 129 